\title{
El Señor de La Producción: Relaciones Entre Agrónomos y Desempleados Rurales en un Proyecto de Construcción de Cooperativas de Trabajo
}

Leandro Etchichury El presente artículo es el resúmen de una investigación realizada en base a un trabajo de campo desplegado a lo largo de los años 1997-1998, en localidades cercanas a la capital de la provincia de San J uan. Se trata de una zona con una fuerte tradición vitivinícola que a partir de los años 1980 fue afectada por una profunda reconversión en el sector, a lo que se sumó los efectos de las políticas de ajuste y de desregulación. Sus consecuencias: reducción de personal por parte de las empresas, precarización de las relaciones laborales, la casi desaparición del contratista de viñas ${ }^{1}$, abandono de fincas pequeñas y medianas, y expulsión de mano de obra familiar del pequeño viñatero. Finalmente la «solución» se manifiesta por dos extremos, éxodo de pobres rurales, por un lado, y concentración de la propiedad y/o producción en un reducido sector altamente tecnologizado, por el otro.

Ingenieros Agrónomos, pertenecientes a la Unidad Minifundios del INTA (Instituto Nacional de Tecnología Agropecuaria) de la zona, abordaron la tarea de contener, a través de proyectos cooperativos, a esta heterogénea masa de desplazados rurales. La homogeneidad de políticas en una heterogeneidad de identidades provocó resultados contrastantes. Esta investigación se centró en el conflicto entre técnicos y ex asalariados rurales que se presentó con la experiencia de cooperativización avanzada en años. Los primeros, inductores externos de un proyecto colectivo; los segundos, desocupados rurales con disímiles experiencias de vida. 


\section{EL AGRÓNOMO Y LA APROPIACIÓN DEL CONOCIMIENTO}

El desarrollo de la agronomía hacia su estatus de ciencia está en directa relación con una etapa en la que se atacó a los sectores campesinos por su atraso, ignorancia e incapacidad para llevar adelante una agricultura moderna, complemento necesario a la revolución industrial del siglo XVIII.

La Inglaterra de entonces cuenta con una importante aristocracia terrateniente, que en su competencia con la floreciente burguesía urbana no duda en adoptar las teorías desarrolladas por J ethro Tull en pos de un uso intensivo de sus explotaciones. El surgimiento de esta clase de grandes agricultores impulsará los estudios agronómicos. Así nace en 1793 el Board of Agriculture importante institución de fomento y progreso agrícola (Mantoux, 1962:140). Además, y como segunda consecuencia de este proceso de desarrollo, la política de enclosures² llevó a la expulsión de sus tierras de un importante sector campesino.

En la Argentina, el sistema de enseñanza agrícola dará sus primeros pasos en 1823 de la mano de Bernardino Rivadavia (Ratier 1989:4).

Será a partir de esta historia que desde las ciencias sociales se verá a la agronomía como una ciencia con un carácter de elite.

«Al agrónomo cabe el monopolio de la ciencia, entendida como sinónimo de verdad, lo que fundamenta su poder en las estructuras burocráticas destinadas a la modernización agrícola, y en el sistema de enseñanza. Como apunta (Claude) Grignon para Francia, la organización jerárquica de esos organismos es determinada en función directa de la distancia respectiva de los profesionales en relación a la clase dominante, a la ciencia y a la ciudad, y en función inversa de su proximidad al campesinado, a la práctica agrícola y al campo. El saber campesino es desvalorizado y opuesto a un saber nuevo, cuya matriz no es la huerta o el corral, sino el laboratorio» (Ratier 1988:53).

El establecimiento de las sedes de educación superior en las ciudades, revalorizándolas como los centros por excelencia de la producción científica, subordinando la práctica a la teoría, marca este carácter. Para el antropólogo Hugo Ratier son éstos los lineamientos del llamado modelo agronómico.

La visión del círculo de Ingenieros Agrónomos como un grupo de estatus tiene sus fundamentos no sólo en la defensa de sus intereses profesionales contra toda intromisión foránea en su área de incumbencia, sino fundamentalmente en su transformación en un grupo intermedio entre una élite hegemónica y los sectores rurales subordinados. Claude Grignon destaca, al analizar el caso francés en su trabajo La enseñanza agrícola y la dominación simbólica del campesinado 
(1975), la pertenencia a la clase dominante de aquellos profesionales que ocupan los puestos de decisión y planificación más altos.

«Dentro del esquema propuesto al ingeniero agrónomo profesional cabeel comando del proceso de modernización de la agricultura, y de las relaciones sociales imperantes en el campo. Dueño de la estrategia, necesita de un profesional subordinado próximo a su especialización pero que no domine el crítico recurso del saber científico (los técnicos agrícolas), para intermediar su relación con quienes habrán de ser modificados, los productores» (Ratier 1986: 18).

Delma Pessanha Neves, en su estudio sobre la construcción del productor moderno, hace mención a una división entre los agrónomos dedicados a la investigación y aquellos dedicados a la extensión rural. Mientras que los primeros son los creadores del saber -posición de privilegio-, los segundos construyen su legitimidad deslegitimando el saber empírico de los productores, a partir de la construcción anteriormente desarrollada del comportamiento social de los agricultores.

Es con estas herramientas que el agrónomo llega a ese proceso de modernización debiendo operar en un contexto de relaciones sociales preexistentes, conflicto de intereses, alianzas, juego de fuerzas políticas, surgimiento de efectos no previstos, de inclusión de unos y exclusión de otros agricultores (Pessanha Neves 1989:107). Asimismo, el propio profesional estará condicionado por sus supuestos político-ideológicos.

En el estudio realizado por Claudia Guebel sobre el programa Cambio Rural, desarrollado por la Secretaría de Agricultura, Ganadería y Pesca del gobierno argentino, se pone de manifiesto toda esta concepción, anteriormente expuesta, cuando se destaca que el programa trata de inculcar, a través del lenguaje y de la organización, una mentalidad empresarial y comercial.

«Por las características de la propuesta, la idea de empresa que se propone tiende mucho más a corresponderse con las sociedades comerciales que con las cooperativas» (Guebel 1997:5).

El choque que se produce cuando la voluntad de cambio del agrónomo se opone al tradicionalismo del productor, es analizado por Guebel en términos de resistencia y desestructuración social.

«...Para ser viable el cambio, (Pierre) Bourdieu plantea la necesidad de una reinvención creadora, como un modo de estructurarse nuevamente después de la desestructuración. Esta reinvención creadora puede ser realizada a través del uso de mecanismos tradicionales, es decir, haciendo jugar lo conocido y lo nuevo juntos» (Guebel 1997:12). 
El problema aquí se presenta cuando se plantea sobre los modos y agentes que operen este cambio, aquellos a los que Guebel llama bisagras. Nos encontramos así en el marco de los programas de Desarrollo Comunitario (Boivin y Casabona, 1983) que buscan integrar a los sectores tradicionales en la progresista sociedad nacional, a través de la mediación de líderes locales que por su adhesión, más o menos espontánea, movilizan a la comunidad en ese sentido.

El tema en estos casos es que habitualmente se parte de la concepción funcionalista de la sociedad equilibrada y sin conflictos, provocando una legitimación de las relaciones de poder existentes, su acentuación o una crisis cuando nuevos líderes son legitimados por el agente de cambio, en virtud de poseer un conocimiento técnico como capital social.

Volvemos a ver, con estas teorías para el desarrollo, concepciones dualistas de un marcado tinte etnocéntrico, que plantean como único modelo evolutivo el occidental, uno de cuyos paradigmas fundamentales es la racionalidad económica.

«En los años 1960, el auge de los modelos de desarrollo inspirados en los 'paradigmas de la modernización', que suponían al mismo como un camino que conduciría a las sociedades 'atrasadas' a un estado de progreso que correspondía a las sociedades 'avanzadas', 'industrializadas' de occidente, provocó en América Latina la implementación de políticas que tendían a la modernización de las sociedades agrarias. Un grupo de ellas tenía como objeto generar y difundir tecnologías, formas de producción y modelos que hacían abstracción de los procesos históricos y de la lógica o racionalidad de los distintos actores sociales. Estos modelos productivistas, que promueve el sistema económico dominante, tienden a priorizar o intensificar la actividad comercial más importante..., con el objeto de producir volúmenes significativos a los fines de la política económica, pero como contraparte su aplicación significa una fuerte competencia entre productores que pretenden ser 'modernos', que necesitan constante apoyo técnico y un gran volumen de créditos para implementar ésas tecnologías. Este modelo ha tenido como consecuencias la desaparición de numerosos productores agropecuarios independientes, migración de poblaciones rurales, subutilización de recursos humanos, degradación y desaparición de los recursos naturales» (Villafañe 1995: 10).

No obstante, siguió perdurando la concepción de que la causa de estos fracasos se hallaba en las «resistencias al cambio» y la consecuente reproducción de «conductas irracionales».

Cuando el antropólogo Norman Long defiende una perspectiva de trabajo centrada en el actor, contempla

«la intervención estatal y la modernización de la agricultura como una serie de procesos 
negociados, continuos y socialmente construidos que involucran actores específicos. No son transformaciones estructurales despersonalizadas sino que implican interacción, competencia, conflicto y negociación entre personas y grupos de orígenes, ideologías y recursos diferenciados. En resumen, están constituídos por series complejas de encuentros sociales e interfases ${ }^{3}$ que involucran a personas con mundos de vida contrastantes, y en ocasiones aparentemente incompatibles» (Long 1994:6).

\section{EL INTA Y SU ROL EXTENSIONISTA}

El INTA, organismo del Estado fundado en el año 1956, nació con el compromiso de alentar la investigación y promover el desarrollo de la actividad agropecuaria en todo el territorio argentino, contemplando la participación de distintos actores rurales.

El accionar de sus Agencias de Extensión tiene por herencia una fuerte impronta de modernización del agro, a través de una transferencia de nuevos conocimientos y nuevas tecnologías acompañadas de pautas de carácter productivista (la búsqueda de la eficiencia con el objetivo de maximizar beneficios).

En 1987 el INTA crea la Unidad de Minifundios (Unidad de Coordinación de Planes y Proyectos de Investigación y Extensión para Productores Minifundistas) con la finalidad de atender las necesidades de los pequeños productores agropecuarios, a través de proyectos instrumentados por las Agencias de Extensión con aprobación y financiación de la Dirección Nacional del citado Instituto.

"El objetivo general de la Unidad Minifundios es contribuir a aumentar los ingresos y mejorar la calidad de vida de los productores minifundistas para posibilitar su transformación en productores capitalizados.

Para la Unidad de Minifundios se entiende por productor minifundista a quien posee una pequeña superficie de explotación, problemas de tenencia de la tierra, mano de obra familiar con baja remuneración, deficiente asistencia técnica y asesoramiento profesional, falta de tecnología adecuada, no acceso al crédito formal, bajo poder de negociación y debilidad organizativa en lo político gremial" (Berenguer 1997:8).

La política de trabajo que plantea la Unidad Minifundios tiende a favorecer la organización colectiva, para una posterior autogestión del proyecto.

En la Argentina las formas cooperativas han adquirido mucha importancia en la conformación de importantes complejos agroindustriales, tales como en los casos de los lácteos, arroz, oleaginosas, 
azúcar y frutícolas. No obstante, el economista Miguel Teubal destaca que el actual contexto de concentración económica, retiro el Estado de su papel promotor y regulador, restricción financiera y relaciones asimétricas entre los actores, junto a las propias dificultades organizativas, dan origen a procesos de crisis que no son fáciles de superar. Según datos del INTA del año 1993, sobre unas 2000 cooperativas de trabajo matriculadas menos de un 10\% llevarían una existencia exitosa. Ligado a esto, Tort y Lombardo destacan la existencia de una relación directa entre los períodos de crisis en la Argentina y el crecimiento en el número de cooperativas de trabajo, fundamentalmente por los procesos de desocupación y dificultades de los sectores medianos y pequeños de la economía (Tort y Lombardo 1993:9).

\section{LA FEDERACIÓN}

La Federación - así la llamaremos de ahora en más (siguiendo el uso de los socios) a la Federación de Cooperativas Agropecuarias - nació de un proyecto de sistemas cooperativos agropecuarios de pequeños productores, elaborado en el año 1987 por técnicos del INTA, a instancias del éxito conseguido con el desarrollo de la Cooperativa de Trabajo Agropecuario y Consumo Del Carmen, en 1983.

Roberto, Ingeniero Agrónomo del INTA cuyo protagonismo en la gestación y desarrollo de toda esta experiencia fue y continúa siendo muy importante, destacó que los principales objetivos de aquella primera experiencia cooperativa fueron «transformar obreros municipales y de viña en productores, desarrollar cultivos alternativos con mira a la exportación e integrar las familias buscando un desarrollo integral».

En informes presentados a la Unidad de Planes y Proyectos de Investigación y Extensión para Minifundistas del INTA se informa que lo que se intenta es:

“Promover y fortalecer el cooperativismo en el sector rural, para generar condiciones socioeconómicas que favorezcan el arraigo de familias rurales, y en segundo lugar, a paliar el déficit de semillas forrajeras y hortícolas nacionales de calidad, sustituyendo su importación y promoviendo exportaciones" (Tort y Lombardo 1993:60).

A partir de entonces sucesivos grupos fueron integrándose al proyecto, con mayor o menor éxito, conformando distintos tipos de cooperativas de acuerdo a las características de las que se 
partían. A grandes rasgos tenemos las de producción (conformadas por pequeños productores), cuya modalidad de trabajo es la unificación de lo producido en las parcelas de cada agricultor para su posterior comercialización; y las de trabajo (integradas por ex trabajadores asalariados), que se caracterizan por la producción y comercialización en común.

Con un total de doce cooperativas, y otros potenciales grupos que se perfilaban para constituirse como tales, apoyadas técnica y económicamente por la Unidad Minifundios del INTA, comienza a principios de la década del 1990 a proyectarse la formación de un organismo de segundo grado que aglutinara y sostuviera a todas las cooperativas. Para 1993 ya estaba organizada y matriculada La Federación.

Las cooperativas se reúnen una vez al año en Asamblea, instancia máxima de decisión, donde se elige al Consejo de Administración (presidente, secretario, tesorero y dos vocales). El Consejo se reúne semanalmente en la sede de La Federación y allí pueden participar representantes de las cooperativas.

A Roberto, se fueron agregando nuevos técnicos (en su mayoría jóvenes recientemente egresados de distintas universidades del país), y en 1998 forman un equipo que suma seis especialistas, cuyos salarios y equipamiento están repartidos entre el INTA, La Federación y el Programa Social Agropecuario (desarrollado por el gobierno nacional y destinado a los pobres rurales). A ellos se suman dos contadores y un plantel administrativo integrado bajo forma cooperativa.

Según los propios técnicos se factura anualmente (1997) alrededor de dos millones de pesos. Los principales ingresos provienen del abastecimiento de variedades de semillas al Plan Nacional PROHUERTA ${ }^{4}$, contrato que vienen obteniendo por licitación pública.

Datos del año 1995, sobre un total de 108 encuestas realizadas a socios de La Federación (espectro que cubre a un total de 386 personas), nos pueden ofrecer un panorama inicial sobre la situación social de las cooperativas:

En relación con el tipo de construcción de casas, con respecto a la protección contra posibles terremotos, se encontró que 44 casos poseen del tipo antisísmico, 60 poseen no antisísmica (adobe) y 4 tienen parcialmente antisísmica. Respecto al tipo de baño instalado o no instalado (retrete), 65 casos poseen instalado, 43 casos no poseen este tipo. En el caso del servicio de electricidad el total de los productores la poseen. En cuanto al agua potable, 62 productores tienen este servicio, 44 no poseen servicio de agua potable y 2 no contestan. En el caso del tipo tenencia de la propiedad 
que se habita se observó que 62 productores viven en casa propia, 6 alquilan y 40 son prestadas. Con relación a la cobertura social de los encuestados, se encontró que 41 casos poseen obra social, 66 casos no poseen de ningún tipo y 1 no contestó. Por último, respecto a los aportes previsionales, se obtuvo que 79 productores no realizan aportes en cajas jubilatorias, 24 realizan estos mismos y 5 casos no contestan.

\section{RELACIONES DE DEPENDENCIA}

Las relaciones de dependencia o subordinación cobran gran importancia para analizar las interrelaciones entre los actores sociales de La Federación.

Diversos autores (entre otros Robert Redfield, Eric Wolf y J ulian Pitt-Rivers) coinciden en la existencia, en el mundo campesino, de lazos de dependencia debido a la reproducción de relaciones asimétricas de poder; reproducción que se extiende más allá de quien podemos calificar como el patrón y su entorno, para incluir otras personas e instituciones conformando una estructura clientelar que abarca al propio Estado. Para Redfield el campesinado se encuentra dentro de sistemas sociales más amplios que generan sentimientos de superioridad e inferioridad y mantienen relaciones de influencia. Veremos que, a diferencia de lo planteado por Hamza Alavi, relaciones de reciprocidad asimétrica y explotación pueden ser elementos complementarios para el análisis.

Durante los primeros días de trabajo de campo uno de los temas que más destacaron los técnicos fue su molestia con los socios de Mala Pata ${ }^{5}$ porque en reiteradas ocasiones habrían expresado extrañar el trabajo con «el patrón». Vale recordar que los socios originales de Mala Pata vienen de una fuerte relación de dependencia con su ex empleador. No sólo trabajaron y vivieron en sus tierras durante mucho tiempo, sino que aún después de rota la relación laboral siguieron viviendo en sus tierras, hicieron algunos cultivos para «el patrón» (bajo la forma de arrendamiento) y su palabra continuó teniendo peso mientras ellos vivieron allí. Cuando se les pide una comparación entre el trabajo anterior y el actual, ellos manifiestan al investigador una satisfacción por la nueva forma de trabajo cooperativo y por ser ellos mismos quienes toman las decisiones. «Ahora uno es un capitán», afirma Pedro.

Cuando se aborda directamente el tema del patrón, aseguran no tener un mal recuerdo del mismo. «Cuando ya no trabajábamos para él nos prestó un camión para tratar de vender una 
producción propia de cebolla (...) Teníamos un salario, obra social y nos pagaba la jubilación», relata Pedro haciendo hincapié sobre temas aún no resueltos con La Federación.

La falta de dinero en mano, de manera regular, es una de las preocupaciones de estos ex trabajadores rurales, tanto de Mala Pata como Las Piedritas ${ }^{6}$, que en momentos críticos los lleva a plantearse un retorno a su anterior condición de asalariados.

La fuerza y arraigo a un modo de vida, en poblaciones rurales subordinadas, es destacada en un estudio sobre los trabajadores de la caña de azúcar en el estado de Pernambuco, Brasil. Su autora, Lygia Sigaud, destaca la permanencia de la ideología del ex morador ${ }^{7}$, aún después de experiencias de luchas políticas y de los cambios producidos por la desaparición de antiguos ingenios azucareros (transformando a los moradores en campesinos o asalariados independientes). Es más, Sigaud afirma que esta ideología se impone aún a aquellos que no participaron de las relaciones de morada, es decir que operan las mismas categorías de pensamiento en aquellos sectores rurales marginados que nunca estuvieron sometidos a un señor del ingenio (Sigaud 1979:44-45).

Dentro de este tipo de relaciones de subordinación podemos incluir las relaciones de tipo clientelar por parte de los cooperativistas en la interacción con el Estado tanto municipal como provincial. Se trata de una búsqueda de beneficios mutuos, de una situación de reciprocidad ${ }^{8}$ («Uno no va a estar recibiendo y no va a dar nada a cambio», plantea una cooperativista), en la que los productores se lanzan a cubrir necesidades propias y de la comunidad que los circunda.

«Los chicos (del vecindario) vienen a tomar la copa de leche acá9. Al llegar, al poquito tiempo, conseguimos el agua potable para la zona. (...) Cuando no había plata, antes de la cooperativa, la Municipalidad nos daba comida. El intendente nos visita. Viene a tomar mate. Lo conocemos desde que era secretario, y con él hablamos lo de la copa de leche. Queríamos hacer un comedor para los chicos, pero no nos da para sostenerlo», cuenta Magdalena.

En una charla junto a otra socia, Luna, que comentaba sobre su adscripción al Partido J usticialista; Magdalena dijo que ella también estaba afiliada al PJ pero sólo por los terrenos que entregaron para construir las casas. Pie de Palo organizó una recepción para el gobernador de la provincia cuando inauguró, medios de comunicación de por medio, el agua potable que los socios venían gestionando para la comunidad.

TÉCNICOS Y PRODUCTORES: EL SABER COMO PODER 
«Usted es el Señor de la Producción». Esta frase contundente y breve, pero que encierra toda una cosmovisión de las relaciones en La Federación de Cooperativas, fue la respuesta que a Gustavo, en su carácter de ingeniero agrónomo, le dio un grupo de socios de la cooperativa Las Piedritas, en voz de Cacho, cuando discutían sobre en quién recaía la responsabilidad de supervisar la limpieza de sus semillas, que se realiza en el campo experimental de La Federación.

En esta construcción de las cooperativas, y posteriormente de La Federación, el papel de los técnicos ha tomado un lugar protagónico que excede la mera asistencia técnica. Los ingenieros agrónomos, junto a los contadores, son quienes dominan la información en La Federación, y ese poder que se construyó y legitimó, fundamentalmente, gracias a una formación de carácter universitario, les permite conformar un sistema con una clara hegemonía de este sector. Se recrean nuevos lazos de dependencia, distintos del patrón, pero que asumen también el carácter económico. De otra manera, los cooperativistas también buscan recrear la voz legitimada de autoridad, pero además cuestionan y critican a esa autoridad. «Nosotros hemos nacido en esta tierra y sabemos también cosas», afirma Cacho, mientras Mala Pata desobedece algunas indicaciones de los técnicos por creerlas erróneas.

Muchas son las situaciones en las que se revelan estos sentimientos de superioridad e inferioridad de los que hablaba Redfield, y que se reconstruyen en La Federación.

Una forma en que se reafirman estas posiciones es a través de los lugares físicos que ocupan los actores ante una actividad de carácter institucional. Ello fue muy significativo verlo en una asamblea anual de aprobación del balance y elección de las nuevas autoridades de la cooperativa ${ }^{10}$.

Luego de una breve charla con los socios sentados al aire libre, frente a una parcela arada recientemente, se decidió pasar dentro del galpón, en momentos en que el sol se ocultaba tras las montañas. Una vez allí, se comienza a armar el escenario. Una mesa larga cerca de una pared lateral a la entrada y enfrentada a una hilera de sillas, contra la otra pared. A su derecha otra hilera de sillas, y cuatro más que están arrimadas a la propia mesa. Cuando cada uno de los protagonistas se va acomodando se termina por armar una escena semejante a un tribunal, de esos que aparecen con frecuencia en las películas norteamericanas.

A la mesa, de cara a los socios, se sientan el presidente y el secretario de la cooperativa. A su izquierda, sentados sobre una cabecera, están los dos contadores (padre e hijo) de La Federación. 108 A la derecha de la mesa, están sentados los técnicos en hilera. Frente a todos ellos, contra la pared 
enfrentada a la mesa, los cooperativistas.

Los contadores asumen un rol protagónico, ya que no sólo decretan en base a los números el éxito o fracaso del año productivo de la cooperativa (que en este caso dio pérdidas), sino también son quienes dirigen las acciones: toman lista, señalan las formalidades a cumplir para la aprobación del balance y la elección de las nuevas autoridades, es decir llevan la voz cantante en el desarrollo de la asamblea. Fiscales y jueces, a un mismo tiempo?

Los técnicos asumen un rol de observación, hasta que al final Roberto se sienta al lado del presidente electo y cierra con un discurso, que termina en diálogo con los presentes, sobre la necesidad de incorporar nuevos socios, en particular jóvenes que aporten dinamismo a las cooperativas. El jurado?

La participación de los socios es más bien discreta. Sus silencios son notorios, pero no absolutos. Preguntas en base a dudas señalan un pensamiento que no termina de ser verbalizado. Son ellos el objeto de juicio?

De llevar hasta el final este juego entre lo imaginario y lo real, nos faltaría encontrar la defensa; que de alguna manera recae en el presidente y secretario salientes que son los únicos cooperativistas separados del resto y que ocupan una posición central en este acto.

Sobre el final de la asamblea hay sillas de los productores que van quedando vacías. Afuera del galpón hay un asado que se va cocinando a las brasas y a su alrededor los socios que salieron hablan animadamente entre ellos ${ }^{11}$. El ambiente de la cena será mucho más vital que durante la asamblea. Las conversaciones van y vienen, y se confunden en múltiples diálogos.

La posición de autoridad que ocupan los técnicos en un proyecto cuyos principios son la autogestión, la igualdad y la solidaridad parece haberse construido en el propio proceso de interacción entre los actores sociales. Un ida y vuelta entre técnicos, cuyo mandato es dirigir un proceso de modernización agrícola en la búsqueda de construir un productor renovado, y un grupo de ex trabajadores rurales cooperativizados que aún no superan una etapa que se supone de transición desde relaciones laborales con un alto grado de dependencia patronal.

Es en esta interacción, entonces, donde los productores trasladan responsabilidades patronales hacia los técnicos. El reclamo de su presencia y dirección surge en todo momento, durante las entrevistas y las conversaciones informales.

«En aquella finca (un importante lote privado con vides) el técnico está todos los días. Señala todo lo que hay que hacer y mire como está» (...) «Ellos (los técnicos) tienen que estar en el campo 
y no allá (en la sede)» (...) «El Ingeniero Roberto es el que dice como son las cosas», son ejemplos de comentarios recurrentes sobre la necesidad de una presencia permanente.

Los agrónomos son conscientes de esta demanda y reconocieron que el crecimiento de La Federación superó su capacidad operativa, así fue que contrataron nuevos técnicos e implementaron nuevos modelos de trabajo que los propios productores reconocen han mejorado la situación. No obstante, sigue el reclamo.

Frente a esta situación se percibe una actitud ambivalente por parte de los técnicos, quienes ante la continuidad de la demanda reconocen y afirman, por un lado, rechazar esa dependencia de los cooperativistas para el trabajo («yo sólo soy un asistente y me piden que sea técnicocapatáz; ellos no salen a defender su lugar como participes principales»). Pero, por otra parte, y principalmente en el caso de los técnicos más antiguos, asumen un rol que se podría calificar del tipo paternalista, llegando incluso a reproducir las anteriores relaciones patronales.

«... Por otro lado está el tema que no sabemos cómo podría funcionar, que es el de los premios y castigos. Yo, en mi caso lo hago con mi hijo. Según una situación buena lo premio. En una situación mala le pego un chirlo en el culo o no le doy la guita el fin de semana. Aquí intelectualizamos que tiene que haber premios y castigos, lo que pasa es que a la hora de castigar se nos derrite todo, viste», relata Roberto al analizar la baja productividad de las cooperativas. «Nosotros, a veces, dijimos 'bueno, el que no presentó la documentación no le vamos a pagar nada, ni el préstamo, ni la semilla, ni la mano de obra de las colecciones, ni la guita para el ómnibus'. Pero cuando te caen y te dicen, 'vea ingeniero necesitamos quinientos pesos para comprar mercaderías y no tenemos un mango', y bueno qué vas a hacer», continuó. Cuando se le pregunta si no hay una actitud paternalista en todo lo expresado, y además centrada en una persona, lo niega enfáticamente. «el tema del paternalismo yo lo tomo con muchas pinzas porque creo que no es el caso de la gente con la que nosotros trabajamos. No hubo igualdad de oportunidades. Nosotros estamos tratando de hacer un esfuerzo para tratar de emparejarla en algunas cosas, sabiendo que partimos con mucha desventaja», aunque reconoce que «puede haber alguna actitud paternalista en algún caso, pero no en el proyecto». Y aquí se llega a uno de los casos más claros de cómo en algunos momentos funciona esta autoridad. Se trata de Carla, una asistente social del INTA que colaboró con el proyecto hasta que los técnicos decidieron separarla. «Esto del paternalismo lo creía la Carla. Ella pensaba que esto era paternalismo, entonces ella iba a las cooperativas y desde el auto pegaba el grito y se iba», afirma Roberto. Para los técnicos el trabajo de la asistente social 
«fracasó porque no le gustaba poner los pies en el barro y mucho menos tomar mate con la gente». En la decisión de incluir a Carla como la pata social del proyecto prevaleció su origen local, hija de una familia humilde. «Es como si hubiese querido renegar de su pasado», se afirmó. Quienes no entendieron así la situación, y se vieron perjudicados con su desplazamiento del proyecto (sin ser consultados), fueron los propios productores, que en palabras de Magdalena se sintetiza ese sentimiento: «Acá venía Carlita y nos ayudaba mucho. Ahora que no está la extrañamos. Tenemos ganas de ir a buscarla para que nos asesore. Con ella teníamos la idea de comprar un horno con un subsidio del PROSOL, pero no se pudo. Ella nos enseñaba cómo vivir mejor». En Las Piedritas fueron los hombres quienes lamentaron la ausencia de la asistente social.

Con la compra de tierras sucede otro tanto. Anteriormente se había afirmado en forma temporaria que las tierras compradas eran de las cooperativas. Esa afirmación no era tan exacta, como se aclaró en su momento. Las tierras se compran a nombre de La Federación y esa decisión se tomó, comentó uno de los técnicos, ante el temor de que se perdieran tanto por desmembramientos de las cooperativas, como por una «mala» decisión de los socios.

Esta forma de ver a los productores llevó a tomar decisiones que terminan reproduciendo las relaciones de dependencia que afirmaron molestarles en otros casos. Cuando en el último viaje comenta uno de los técnicos la mejor situación que vivía Mala Pata, relata sobre la distribución en las cooperativas de un crédito del Banco Interamericano de Desarrollo (BID), que ante la visión villera ${ }^{12}$ que se construyó sobre Mala Pata se decidió, «con todo éxito», que para evitar que tuvieran todo el dinero junto, y se malgastara, ir entregándolo en cuotas a cada socio, «a modo de jornal».

«Yo reconozco que muchas veces antes de que el Concejo (de La Federación) decida nada primero me miran a mí. Yo no me puedo sentar atrás en las reuniones. Es una situación jodida, difícil de manejar. Como yo estoy todo el tiempo soy el que sabe los distintos temas y puedo dar una visión global de la situación», afirmó Roberto sobre el final de una larga conversación en la que se trató de arribar a este tema. «A veces he pensado si la solución no sería rajarme cuatro meses, pero tampoco se si me bancaría cuatro meses sin pasar por aquí. No es tan fácil borrar todo y decir 'bueno señores esto es un proyecto participativo, anónimo', es utópico». 
Si uno se deja llevar por los principios desarrollistas de los técnicos, en cuanto a modernización y conformación de un sujeto eficiente, no podemos considerar como alcanzada esa meta en cuanto se refiere a nuestros productores cooperativizados. En principio, podríamos hablar de una transición, que en algunos casos lleva quince años ${ }^{13}$, y que parece más desorientar a los técnicos que darles certezas sobre la llegada al tan ansiado destino.

Las expresiones de temor ante el fracaso no se hacen esquivas. Ante ese posible escenario y diferenciando a las cooperativas conformadas por agricultores de oficio de las integradas por ex trabajadores, Roberto afirma: «Es distinta la situación, porque es distinta la actitud que uno puede esperar del pequeño productor, que era individualista como el caso de El Porvenir, el caso de Iglesias ${ }^{14}$, ante un fracaso generalizado. Ellos estuvieron en la lucha y vuelven a la lucha (...) Ahora, las cooperativas donde eran solamente obreros, y muy dependientes, caerse yo creo que sería catastrófico. Probablemente significaría villa miseria. Ellos no van a saber autosostenerse, no van a saber pelearla. Están, hoy por hoy, muy respaldados en la estructura general».

Esa estructura general es La Federación y sus técnicos. Este discurso es muy fuerte y los productores lo asumen de alguna manera. «No podemos destetarnos de La Federación», dijo Pedro en una oportunidad en que reconocía la crítica situación productiva de la cooperativa.

Aún así, los productores son más conscientes de que tuvieron un pasado precooperativo, en el que vivieron (o tal vez sobrevivieron) de su propio esfuerzo y con sus propias estrategias. De esta forma, los actuales cooperativistas hacen una evaluación con diferente enfoque sobre el pasado, el presente, el cambio. Esa evaluación es variable, porque es variable la situación de las cooperativas. Así, mientras Mala Pata en todo momento afirmó estar ahora que son cooperativa en mejores condiciones, sin por ello criticar a su ex patrón; Las Piedritas pasó de una situación de afirmar vivir «mejor que antes» (un antes precooperativo), a una sensación de estar peor que en esas etapas previas.

En 1997, Cacho afirmaba: «Estamos mejor que antes (...) Es importante el cambio de pasar de depender del patrón a ser uno el que toma las decisiones. Salir de la explotación, de que haya uno controlando y dirigiendo...», para después mirar a los socios ocasionalmente presentes y conminarlos con un: «Bueno, hablen un poco che!».

Ya en 1998 el discurso había cambiado, la crisis estaba instalada. «Estamos peor que al principio», aseguraba. «Así no podemos seguir, nos conviene trabajar afuera...», afirmaría Marcos. Y luego un contraste que busca mostrar la ruptura de una reciprocidad implícita: «La Federación 
está cada día más rica, mientras nosotros estamos en la miseria».

El cambio es constante y no toma un solo sentido, por ello la desestructuración y la estructuración de una nueva identidad se hace compleja. $Y$ no sólo debe entenderse aquí que se trata de la identidad de trabajador asalariado.

J osé, hermano de Cacho, recordó lo difícil que fue convencer a «los más viejos» a abandonar la producción de vid. Cacho acotó en ese instante, «fue el caso de él». «Por eso se integraron los más jóvenes al principio», continúa J osé, «son los que menos problemas tienen para adaptarse».

La uva formó gran parte de la vida de los pequeños productores y obreros que hasta comienzos de los años 70 vivían de ella, y que aún hoy para muchos sigue siendo el desvelo de sus sueños.

«Los técnicos tienen que aprender algo de lo social. Tienen que ver que el productor debe cambiar despacito la mentalidad», explicaría Cacho mientras observaba los barbechos de vid ${ }^{15}$, una nueva forma de acercarse a un viejo amor .

\section{CONCLUSIONES}

Haciendo una rápida y breve síntesis sobre las valoraciones (positivas y negativas) que los actores ponen en juego, nos encontramos a grandes rasgos con los siguientes datos:

1- Los productores, asignan a la asistencia que brindan los técnicos un importante valor tanto en lo productivo como en un plano social más amplio. De allí la importancia que asume la figura del Ingeniero Roberto, que de alguna manera por su activo protagonismo en la gestación del proyecto es un gran padre (el valor de su palabra), y la Federación vista como algo propio, lejano y superior a la vez, una madre de la que cuesta «destetarse». La imagen del técnico como dador de conocimientos fue rescatada en numerosas ocasiones.

En contraparte, los cooperativistas reclaman entre otras cosas: una mayor presencia de los técnicos en el campo, mayor transparencia de la información y decisiones que toma la Federación (a la que ven manejada sólo por los técnicos y el personal contable-administrativo) y un mayor apoyo financiero por parte de la misma, que se asemejaría en lo fundamental al pago de un salario.

2- Por su parte, los técnicos resaltan una serie de obstáculos que según ellos entienden son los responsables de no alcanzar la ansiada eficiencia productiva. Así, nos encontramos con que 
estos productores son vistos con poca voluntad de trabajo, escasa responsabilidad y propensos al asistencialismo, dependientes de una mentalidad de relación patronal y sometidos a liderazgos internos autoritarios y perniciosos, con dificultad para asimilar nuevos conocimientos y por lo tanto sujetos desvalidos para actuar en la sociedad en forma individual.

De lo relevado en los sucesivos trabajos de campo, resulta importante destacar que estas caracterizaciones, cargadas de un fuerte componente valorativo, si bien al estar internalizadas en los actores operan en sus relaciones recíprocas, fueron exteriorizadas utilizando al investigador como intermediario. Los cooperativistas tratando de hacerles llegar así su visión a los técnicos, y éstos remarcándole los aspectos que creían necesarios modificar para avanzar en sus objetivos.

En conclusión, la experiencia de La Federación asume en su desenvolvimiento las particularidades de los programas de intervención que buscan promover el desarrollo en aquellas comunidades tradicionales y/o marginadas del progreso, como forma supuesta de mantener los vínculos con la sociedad nacional.

Cuáles son los puntos sobre los que se basa esta afirmación? Para empezar, se parte de un ente estatal, como es el INTA, agente inductor del proyecto y cuyos brazos ejecutores son los técnicos. Con esto no se pretende negar el rol activo de los productores en la formación y desarrollo de las cooperativas, como ya se ha visto.

Volviendo, entonces, el INTA (y en particular a través de la Unidad de Minifundios) como agente de cambio tiene entre sus objetivos promover el desarrollo de la actividad agropecuaria, buscando la transformación de los productores minifundistas en productores capitalizados. Para ello cuenta con la ya famosa receta a base de inyecciones de tecnología y recursos económicos. Sus instrumentos, los ingenieros agrónomos son los encargados de operar el programa en un contexto de relaciones sociales preexistentes, transformándose en un grupo intermedio entre una élite que aprueba o no políticas y los sectores rurales subordinados.

El cambio es planteado como posible, y para ello se proponen vencer la resistencia que ejerce la barrera del «tradicionalismo». Así se puede entender que el principal objetivo, cuando comienza a desarrollarse el proyecto, sea el de transformar obreros municipales y de viña en productores hortícolas eficientes. Para ello la herramienta es favorecer la autoorganización a través de cooperativas, que por escasez de recursos y falta de capacitación comienzan siendo tuteladas por los técnicos. Siguiendo las nuevas modalidades de trabajo en planes de desarrollo, La $1 \mathbf{1 4}$ Federación incluyó la labor de una asistente social (como forma de aportar otra visión a la técnico- 
económica), pero su trabajo generó conflictos y fue separada.

A quince años de iniciada la experiencia, La Federación ha crecido cuali y cuantitativamente, pero los técnicos no sienten que los ex trabajadores rurales hayan dado el salto, la situación no termina de estabilizarse y la autogestión comienza a ser gestión de los propios técnicos.

Esta apropiación del proyecto por parte de los técnicos lleva a la paradoja de reproducir relaciones de dependencia previas, en pos de un discurso de transformación.

Es aquí donde el caso, objeto de este estudio, revela la vigencia del problema teórico planteado en el presente trabajo: La reproducción de las relaciones de dominación hacia el sector que conforman los pobres rurales, apoyada en la hegemonía que se construye sobre la apropiación de un saber institucionalmente legitimado.

A falta de una respuesta contundente a favor del desarrollo, la modernización y la eficiencia productiva, los técnicos refuerzan una postura tutelar. Los cooperativistas ocupan el lugar de menores que deben ser premiados o castigados, retados por no cumplir con sus tareas, obedientes a las normas que se imponen para su bien (prohibición de la reelección del presidente de la cooperativa), desvalorizados en su capacidad de sobrevivir por si mismos, privados de la propiedad de las tierras por miedo a la falta de responsabilidad, privados de informaciones sobre el rumbo de La Federación. Así, el lugar de la dominación no ha desaparecido, más bien se ha transformado, pero siempre basado, como afirma la antropóloga Ana María Lorandi, en la supuesta inferioridad del dominado. De ahí al rol del patrón no queda mucha distancia para que se permita esa reinvención creadora, que conlleve a una reestructuración social de los ex obreros rurales.

Meses después de haber finalizado el trabajo de campo me fue relatada una historia de una reciente huelga, en reclamo de "aumento salariales", que cooperativistas rurales de la provincia de Santiago del Estero, tambièn ex obreros agrìcolas, realizaron contra los ingenieros agrónomos que tenían por misión tan sólo la de ser una apoyatura técnica. Para los productores encarnaban la figura del patrón.

Llegados a este punto, nos encontramos con dos actores sociales que portan mundos de vida contrastantes y cuya interacción es sumamente conflictiva. Prefiero hablar de mundos de vida y no de lógicas, ya que este último término comporta una conceptualización encorsetada que impide abarcar las múltiples estrategias que son capaces de llevar adelante los agentes.

Esa interfase de la que habla Long, como lugar donde estos mundos de vida se entrelazan, es en La Federación una gran confusión. 
Los técnicos se molestan porque los socios reclaman de La Federación un rol redistribucionista, más aún cuando ven su crecimiento frente a la crítica situación que viven. Pero ese reclamo no ejerce su peso en las reuniones de Concejo de La Federación. Un sentimiento de falta de información lleva a los socios al silencio. Ahora el silencio no implica apatía, como entienden los técnicos. Allí se expresan dudas, temor, inseguridad. El silencio no significa que no haya nada para decir y generalmente esos pensamientos se canalizan en el intercambio con los pares, y en este caso con el investigador.

Así también, la «vagancia» y el «asistencialismo» son señales para los técnicos de la poca voluntad de trabajo. Pero también se puede entender que los cooperativistas desconocieron la maximización de beneficios por vivir una realidad de necesidades básicas insatisfechas. Ante esto las más variadas estrategias de sobrevivencia (calificada como «lógica villera») se hacen válidas, siempre que sirvan para enfrentar un nuevo día: la producción agrícola puede ser tan importante como la búsqueda de trabajo asalariado, como el autoabastecimiento, como las transferencias formales desde el estado u otros entes, como la capacidad de integrar redes de solidaridad (de Dios 1998: 124).

Los cooperativistas se sienten como «capitanes» cuando hablan de su actual vida cooperativa, en referencia al pasado; y se autoadscriben como obreros cuando reclaman asistencia a La Federación y a los técnicos. Cuando la cooperativa más que una opción es un salvavidas frente a la crisis económica, autores como Giarracca afirman que las situaciones de subordinación tienen su continuidad al buscar minimizar los riesgos en la toma de decisiones (Giarracca, 1994:15), más aún cuando la experiencia laboral de un obrero rural prácticamente no atraviesa por la toma de decisiones en forma autónoma. Por otra parte, investigadores ${ }^{16}$ que han trabajado en los últimos años el tema de asalariados rurales coinciden en que aquellos actores que han entrado en este tipo de relaciones laborales muy difícilmente puedan abandonarlas para dedicarse exclusivamente a la producción agrícola. Entre los motivos se encontrarían tanto cambios en los hábitos de consumo, como cambios en los ciclos del trabajo rural. Así no suena ilógico que entre las estrategias de subsistencia se plantee emplearse por veinte pesos semanales o estar a la pesca de subsidios que representen dinero en efectivo para la compra de bienes. Esta situación nos lleva a dudar respecto a la pertinencia de un laxo concepto de campesino, el cual debería ser reconsiderado ante comportamientos que nacen de representaciones que les son propias y que los separan de aquellos actores ligados a su tierra y que para sobrevivir no venden su fuerza de trabajo. 
Finalmente, con todo esto no se busca cuestionar los proyectos de desarrollo, al modo de la Antropología del Desarrollo que considera a este concepto como una invención históricamente determinada que busca la preservación de un determinado orden, tanto fuera como dentro de los estados nacionales. Una forma cultural, una invención, que podría desinventarse o reinventarse de otras formas (Escobar 1998:9). Pero sí concluir que toda propuesta de desarrollo rural, que lleva implícito un alto contenido de cambio, no podrá contemplar la posibilidad del éxito si no cuestiona y replantea la organización del poder, cuanto menos en el ámbito que abarcará el proyecto.

Leandro Etchichuryé pesquisador do núcleo de Antropologia Rural da Faculdade de Filosofia e L etras daUniversidadedeBuenosAires. É membro do Instituto de Investigaciones Antropológicas de Olavarria(IIAO), da província de Buenos Aires, e assessor das comissões de População e Cultura da Câmara de D eputados da Nação (Argentina). 


\section{NOTAS}

1 Los contratistas de viñas tienen a su cargo el manejo del cultivo, utilizan mano de obra fundamentalmente familiar, aunque pueden contratar personal asalariado en forma temporaria. La comercialización generalmente está en manos del propietario de la explotación.

2 cercamientos

3 «El análisis centrado en el actor social se orienta a tres cuestiones: la explicación de la heterogeneidad y su significado social; el análisis de las situaciones de interfase donde los mundos de vida de los actores se entrelazan, se acomodan o chocan entre sí; y el delineamiento de las capacidades que manifiestan las prácticas organizativas particulares para efectuar el cambio» (Long 1994:4)

4 Se trata de un programa de carácter nacional que busca promover, fundamentalmente en sectores empobrecidos, el desarrollo de huertas para el autoabastecimiento comunitario. Para ello abren anualmente una licitación para la provisión de distintas variedades de semillas hortícolas al plan.

5 Ubicada en una zona con una traumática historia sismológica, Mala Pata es una de las primeras cooperativas de trabajo que conformaron el proyecto. Debe su nombre al cerro que los cobijó en sus primeros pasos, cuando un grupo de hombres, obreros de viña, se quedaron primero sin trabajo y luego sin vivienda debido a que "el patrón" decidió suspender toda producción en sus tierras. Así, comenzaron arrendando tierras a su ex empleador, quien les cedió en uso la superficie para las viviendas, prolongando de esta forma los lazos de dependencia.

6 Las Piedritas es, en primer término, un pequeño poblado compuesto por 28 familias, lugar donde nace la cooperativa que se irá desarrollando con el aporte de trabajadores viñateros desempleados. Cacho es uno de los principales referentes del grupo, formado al calor de las luchas sociales de los años 1960 y 1970; cuyo liderazgo hoy se ve cuestionado por un joven socio, Marcos, que cuenta con el apoyo de los técnicos por "su visión moderna" respecto al modo de llevar adelante el trabajo.

7 Los moradores fueron la fuerza de trabajo utilizada en los ingenios azucareros en Pernambuco, quienes además vivían en la propia hacienda, estableciéndose de este modo fuertes lazos de dependencia con el propietario.

8 Que también se plantea para con la Federación

9 Una idea que los cooperativistas gestionaron ante la Municipalidad como forma de acercarse a la comunidad.

10 Se trata de la cooperativa Del Carmen, que si bien no estaba incluida en las dos cooperativas elegidas para el presente trabajo fue la única oportunidad de participar de una actividad de este tipo que, según afirmaron los técnicos, no difería de las asambleas que se realizan en las otras cooperativas.

11 La comida como corolario de un encuentro al que se le asigna cierta importancia estuvo presente a lo largo de esta investigación. La Federación está conformando un fondo para estas celebraciones gastronómicas. Estos momentos son importantes para rescatar datos. En ocasión de la inauguración del agua potable en Mala Pata, con la visita del gobernador, se generó un conflicto entre Luna y La Federación por la negativa de esta última a liberar los fondos requeridos para la comida. Allí Luna puso en juego su capacidad de liderazgo, y la situación terminó en una transacción. Dispusieron de fondos para una comida más modesta que la pretendida. En otro momento, como finalización de una visita de capacitación a la Estación Experimental del INTA «La Consulta» (Mendoza) se realizó un almuerzo en el cual los técnicos ocuparon la cabecera de la mesa y a continuación se sentaron los productores.

12 Las villas de emergencia en la Argentina son lo que las favelas en Brasil. Respecto a Mala Pata, la agrònoma Gabriela cree que los socios «no tienen una lógica campesina, sino una lógica villera. A ellos les gusta comprar bienes de consumo, equipos de música, televisores, hasta unas motitos. Pero a la vez, buscan subsidios que se los comen para vivir y poco para producir en mejores condiciones. Viven del subsidio».

13 Cooperativa Del Carmen.

14 Cooperativas que forman parte de La Federación. 
15 Se trata de varas de una variedad de uva, que se tapan con tierra hasta su brote y luego se venden para armar los parrales. La Federación recién inicia su experiencia en este tipo de producción.

16 Es el caso del sociólogo Roberto Benencia (docente en la Facultad de Agronomía de la UBA). 


\section{REFERÊNCIAS BIBLIOGRÁFICAS}

ALAVI, Hamza. 1976. Las Clases Campesinas y las Lealtades Primordiales. Barcelona: Anagrama.

BERENGUER, Paula. 1997 Federación de Cooperativas Agropecuarias de San J uan: Su relación con el INTA. Monografía para la Cátedra Seminario de Campo III. Facultad de Agronomía (UBA).

BOIVIN, Mauricio y CASABONA, Victoria. 1983. Desarrollo Comunitario: la Reproducción de la Desigualdad. Ponencia presentada en el Primer Congreso Argentino de Antropología Social.

CHAYANOV, Alexander. 1974. La Organización de la Unidad Económica Campesina. Buenos Aires: De Nueva Visión.

de DIOS, Rubén. 1998. "Políticas para la Pequeña Producción Agropecuaria o el Derecho a Permanecer". Realidad Económica, 158.

ESCOBAR, Arturo. 1998. “Antropología y Desarrollo”. Revista Internacional de Ciencias Sociales. UNESCO. Página de Internet.

GIARRACCA, Norma. 1990. “El Campesinado en la Argentina: un Debate Tardío”. Realidad Económica, 94. . 1996. "Procesos de Globalización y Cambios en la Agricultura Argentina”. Globalización, Integración Regional y Consecuencias Sociales sobre la Agricultura. Diego E. Piñeiro (comp.), Universidad de la República del Uruguay.

. s/f. Las Teorías Sociales y los Modelos de Interpretación del Desarrollo Agrario. Las vías de desarrollo agrario. Ficha de cátedra de Sociología Rural. Facultad de Ciencias Sociales (UBA).

. 1994. Acciones Colectivas y Organización Cooperativa. Reflexiones y Estudios de Caso. CEAL. Buenos Aires.

GRIGNON, Claude. 1975. La Enseñanza Agrícola y la Dominación Simbólica del Campesinado. Buenos Aires: Universidade de Buenos Aires, Departamento de Antropología Rural.

GUEBEL, Claudia. 1997. Políticas Públicas y Comunidad Local. El Caso Cambio Rural. Informe Final de Actividades de la Beca de Reinserción.Universidad de Buenos Aires.

HEYNIG, Klaus. 1982."Principales Enfoques sobre la Economía Campesina". Revista de la CEPAL, 16.

KAUTSKY, Karl. 1974. La Cuestión Agraria. México: Siglo XXI.

LONG, Norman. 1994. Cambio Rural, Neoliberalismo y Mercantilización: el Valor Social desde una Perspectiva Centrada en el Actor. Zamora: Colegio de Michoacán.

. 1992. Battlefields of Knowledge. Routledge. Londres. Traducción para uso interno de la cátedra de Sociología Rural, Facultad de Ciencias Sociales (UBA).

LORANDI, Ana María. 1988. «El Servicio Personal como Agente de Desestructuración en el Tucumán colonial». Revista Andina, año 6, 1. Cusco.

MANTOUX, Paul. 1962. La Revolución Industrial en el Siglo XVIII. Madrid: Aguilar.

NOTI-AGRO, San J uan. Publicación del Instituto de Investigaciones Económicas y Estadísticas (Gobierno de 
San J uan) y el INTA (San J uan). Nº6, 1996.

PESSANHA NEVES, Delma. 1984. "As Políticas Agrícolas e a Construção do Produtor Moderno". Ciências Sociais Hoje. Sao Paulo: Vértice.

PINTO CONTRERAS, Rolando N. 1991. Extensionista Agrícola: ¿Educador Rural? El Carácter Educativo de la Capacitación Tecnológica con Productores Campesinos. Santiago de Chile. Programa Interdisciplinario de Investigaciones en Educación (PIIE).

PITT-RIVERS, J ulian. 1971. Los Hombres de la Sierra. Ensayo Sociológico sobre un Pueblo Andaluz. Barcelona: Grijalbo.

RATIER, Hugo. 1986. El Modelo Agronómico: Aproximación desde el Sistema de Enseñanza Agrícola Brasileño. Ponencia en el Segundo Congreso Argentino de Antropología Social. . 1988. “De Campesinos a Técnicos Agrícolas: Conformación de una Categoría Profesional en el Nordeste de Brasil". Etnia, 33. Olavarría.

1989. Técnicos Agrícolas de Nivel Medio en la Región Pampeana: lo Científico y lo Reformatorial en su Producción. Ponencia en el Tercer Congreso Argentino de Antropología Social.

REDFIELD, Robert. 1956. Peasant Society and Culture. Chicago: The University of Chicago Press.

SEMISA, D. 1988. Manual de Cooperativas de Trabajo. Buenos Aires: Intercoop.

SIGAUD, Lygia. 1979. Os Clandestinos e os Direitos. Estudo sobre Trabalhadores da Cana de Acúcar de Pernambuco. Sao Paulo: Duas Cidades.

TEUBAL, Miguel 1995. Globalización y Expansión Agroindustrial. Buenos Aires: El Corregidor.

TORT, María y LOMBARDO, Patricia. 1993. Las Cooperativas de Trabajo Agropecuario en la Argentina. Buenos Aires: INTA.

VILLAFAÑE, Alicia G. 1995. «Producción Familiar en el Agro, Modelos Productivistas y Transformación Estructural. El Caso de Productores Ganaderos de la Región Pampeana Bonaerense». Etnia, 40-41. Olavarría.

WOLF, Eric. 1980 «Relaciones de Parentesco, de Amistad y de Patronazgo en las Sociedades Complejas». Antropología Social de las Sociedades Complejas. Michael Banton (comp.), Buenos Aires: Alianza Editorial. 


\section{RESUMEN}

Ingenieros agrónomos y ex trabajadores rurales, mundos de vida distintos que confluyen en un proyecto colectivo, en medio de la crisis socio-económica provocada por la reconversión de los años 1980-1990 en una región viñatera cuyana (área geográfica argentina comprendida por las provincias de San J uan, Mendoza y San Luis). El presente trabajo pretende bucear en esa heterogeneidad con la finalidad de encontrar los distintos significados que construyen los actores sociales respecto al otro, la propia identidad y al sentido del cambio. Así, la voluntad cooperativista se revela como necesaria pero insuficiente para desterrar las relaciones de dominación.

\section{ABSTRACT}

Agricultural engineers and rural workers present distinct world values that conflate in a collective project, during a socio-economic crisis due to the "reconversión" of the 80's and 90's in the "Cuyana" viticultural region in the provinces of San J uan, Mendoza and San Luis. This article aims to trace this heterogeneity in order to find the distinct meanings constructed by social actors in relation to the others, their own identity and the meaning of change. The "cooperativista" desire reveals itself as necessary but also insufficient for the end of relations of domination. 